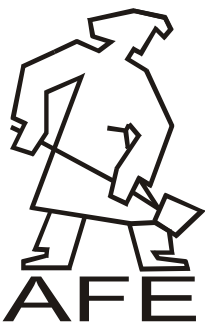

of

FOUNDRY ENGINEERING

ISSN (2299-2944)

DOI: $10.2478 /$ afe-2013-0045

Volume 13

Issue $2 / 2013$

\title{
The Influence of Benzoyl Peroxide on Gelation Rate of Silica Binder for Precision Casting
}

\author{
M. Nadolski *, Z. Konopka, M. Lągiewka, A. Zyska \\ ${ }^{a}$ Department of Foundry, Technical University of Częstochowa, Al. Armii Krajowej 19, 42-200 Częstochowa, Polska \\ * Corresponding author. E-mail address: nadolski@wip.pcz.pl
}

Received 21.01.2013; accepted in revised form 07.05.2013

\begin{abstract}
Substituting of ethyl silicate with ecologic sols of colloidal silica in the investment casting technology, resulting from the increased demands concerning environmental protection, caused the prolongation of production cycle for precision castings produced in multi-layer thin-walled ceramic shell moulds. Modification of Sizol 030 binder with benzoyl peroxide, proposed in the paper, was aimed at restriction of time needed for realization of a single layer of the shell mould, and by the same, of such a mould as a whole. Examination of kinetics of the drying process were held for the layers made of prepared moulding material and the influence of binder modification on the mould curing time was determined.
\end{abstract}

Keywords: Precision casting, Moulding material, Colloidal silica

\section{Introduction}

Application of water-based binders in precision casting [1] evoked again the already well-known problems: the poor wettability of pattern set, the lowered strength at the stage of partial ceramization, the long drying time before applying a subsequent coat and the long final drying of the completed shell. The prolonged time of shell production led to the decrease in productivity of precision foundries. This in turn enforced research works directed towards the elimination of the long drying time inconvenience and towards increasing the rate of the sol-gel transition within the binder. The rate of the gelation process can be increased by physical methods (i.e. by facilitating the water evaporation through proper selection of the temperature, the humidity and the air motion rate), as well as by chemical methods (i.e. by applying chemical substances changing $\mathrm{pH}$ of the binder) [2]. The most common gelation method used for precision castings is drying, during which the hydroxyl groups at the particle surfaces are concentrated because of water evaporation and form the oxosilane bounds (Si-O-Si) [3]. One can distinguish the intermediate and the final drying, the latter preceding the dewaxing process. It is assumed that the intermediate drying is much more important than the final one, because it is decisive for the shell quality [4].

A typical mould made with the use of colloidal silica binder requires for air or vacuum drying for the period of 8 to 10 hours, depending on the shape of the cast part, to achieve proper solidification. The drying time before applying a subsequent layer can even exceed 24 hours if the shell has niches, pockets etc. 
Recent years have brought several experiments which has been aimed to improve the properties of silica-bound materials and to accelerate the binding process. Many types of latexes have been tried: acrylic, vinyl acetate, polysulfide, butadieneacrylonitryle, polychloroprene, styrene-butadiene and other ones [5-7]. The most popular latexes in precision casting are butadienestyrene ones, which co-operate well in mixtures with colloidal silica and do not evolute pernicious substances during the mould burnout. Applying of polymer-modified binders deteriorates the mould strength after its burnout, but improves mould permeability and flexibility. Latexes protect the formerly built coats from soaking by binding and impregnating the colloidal silica particles in the course of drying. They are responsible for generation of the vapour-permeable, but water-impermeable layer, which restricts soaking and quickens drying.

Other methods of increasing the rate of drying and the mechanical strength of shells include e.g. applying silica sol with $40 \% \mathrm{SiO}_{2}$ concentration in the colloidal mixture and the silica particles three or even four times larger than usual [8]. Moulding materials can also be modified by introducing powders: industrial or volcanic ashes, pozzolan, tuff, or microsilica powders [5]. Gelation time of a mixture containing colloidal silica can be also controlled by adding ammonium carbonate, ammonium chloride, or neutral soda $\mathrm{Na}_{2} \mathrm{CO}_{3}$. Drying of an individual layer lasts usually for $4 \div 8$ hours, the most efficient systems achieve $1 \div 2$ hours' drying time [5].

An attempt of accelerating the silica gelation by using sodium fluoride $(\mathrm{NaF})$ is described by Guerra $[4,11]$. Unfortunately, the achieved colloidal binder is not stable, i.e. has a tendency to transform into gel already before being added to the mixture. Elsewhere [12] Guerra presents also the method of producing shell moulds by applying positively charged colloid along with organic or inorganic gelating base. Both the previously mentioned gelating system, and the latter one did not allow for obtaining well hardened material of suitable strength.

The polymer-modified binders are the objects of many patents, e.g. by Guerra [12] and Doles [9], as well as of a domestic invention [10]. At first they were somewhat restricted, e.g. by the demand of using fused silica matrix [11]. This restrictions, however, were overcome, as is exemplified by REMASOL, ADBOND B, or LUDOX AS-40 products. It should be mentioned that applying the polymer-modified binders decreases slightly the strength of a mould after burnout due to destruction of the organic phase, but increases its flexibility and permeability.

\section{Methods of investigation}

The ceramic slurry was prepared in the following way: zirconium flour was gradually added to the measured portion of Sizol 030 colloidal silica, until the outflow time measured for the No. 4 Ford cup was equal to about $20 \mathrm{~s}$. This time was measured after 15 minutes from the moment of introduction of the filler portion and then after 24 hours.

The components were mixed in a rotational tank at the rate of about $10 \mathrm{rpm}$ both while the filler was added to the binder and during the further stages of slurry preparation.

Benzoyl peroxide was added to the slurry prepared in the above mentioned way in the quantity of 0.5 or 1 mass percent of the binder, the examination of the outflow time by means of the Ford cup being not repeated.

The prepared slurry was applied to the one side of polycarbonate pattern plate of dimensions $200 \times 150 \times 1 \mathrm{~mm}$, the superfluous material was allowed to run down by its own gravity for about $15 \mathrm{~s}$, then zirconium flour was rained over the slurry-coated plate. Loose material, which was not wetted with the slurry, was gravitationally dropped down from the specimen surface. Such prepared material was placed in the laboratory drying oven and subjected to the gravimetric analysis, the measurements being accurate to $0.01 \mathrm{~g}$. The following parameters were kept constant during the examinations: air humidity $(60 \pm 5 \%)$, temperature inside the drying oven chamber $\left(22 \pm 2^{\circ} \mathrm{C}\right)$, rate of air motion above the specimens $(0 \mathrm{~m} / \mathrm{s})$. The mass of each specimen was checked every 10 minutes for 3 hours and the mass loss was recorded. Results are presented in Table 3.

The initial mass of every specimen was equal to $20 \mathrm{~g}$ in order to compare the dehydration rates.

After drying, the quality of each obtained ceramic shell was visually checked and compared with the quality of the other ones.

\section{Results of investigation}

The results of gravimetric analysis which allow to determine the dehydration time for the mould material specimens are presented both in tabular (Table 1) and in graphic (Fig. 1) form.

Table 1.

Proceeding of material dehydration

\begin{tabular}{cccc}
\hline & \multicolumn{3}{c}{ experiment type } \\
\cline { 2 - 4 }$\left[\begin{array}{c}\text { time } \\
\text { hh:mm] }\end{array}\right.$ & Sizol030 & $\begin{array}{c}\mathrm{C}_{14} \mathrm{H}_{10} \mathrm{O}_{4} \\
\text { mass percent }\end{array}$ & $\begin{array}{c}\mathrm{C}_{14} \mathrm{H}_{10} \mathrm{O}_{4} \\
\text { mass percent }\end{array}$ \\
\cline { 2 - 4 } & \multicolumn{3}{c}{ mass [g] } \\
\hline $00: 00$ & 301.09 & 232.00 & 219.94 \\
\hline $00: 10$ & 297.62 & 231.41 & 218.82 \\
\hline $00: 20$ & 295.15 & 230.40 & 217.07 \\
\hline $00: 30$ & 293.33 & 229.22 & 215.47 \\
\hline $00: 40$ & 291.69 & 228.33 & 214.52 \\
\hline $00: 50$ & 290.40 & 227.32 & 213.69 \\
\hline $01: 00$ & 289.61 & 226.48 & 213.35 \\
\hline $01: 10$ & 288.91 & 225.74 & 213.23 \\
\hline $01: 20$ & 288.25 & 225.05 & 213.14 \\
\hline $01: 30$ & 287.79 & 224.51 & 213.19 \\
\hline $01: 40$ & 287.41 & 224.15 & 213.03 \\
\hline $01: 50$ & 287.08 & 223.94 & 213.16 \\
\hline $02: 00$ & 286.80 & 223.8 & 213.18 \\
\hline $02: 10$ & 286.53 & 223.78 & 213.16 \\
\hline $02: 20$ & 286.30 & 223.76 & 213.15 \\
\hline $02: 30$ & 286.10 & 223.75 & 213.14 \\
\hline $02: 40$ & 285.92 & 223.73 & 213.13 \\
\hline $02: 50$ & 285.72 & 223.70 & 213.09 \\
\hline $03: 00$ & 285.59 & 223.71 & 213.09 \\
\hline $03: 10$ & 285.46 & 223.70 & 213.11 \\
\hline & & &
\end{tabular}




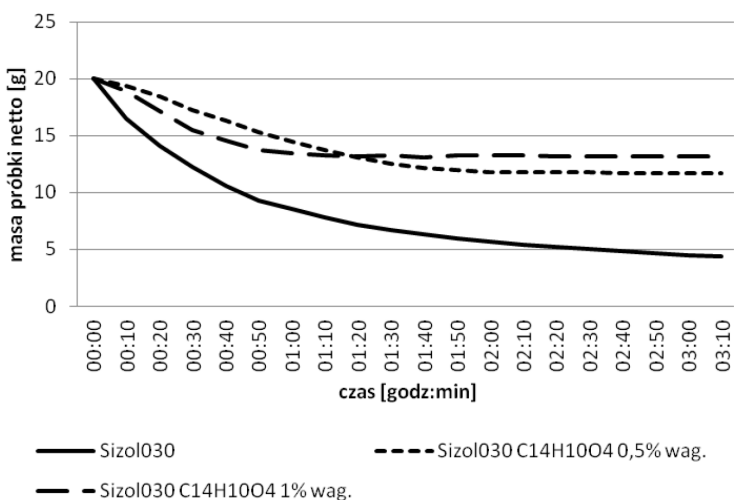

Fig. 1. Gravimetric analysis of mass losses of the specimens during drying of shells

The obtained specimens of moulding material were visually checked. Observation results concerning the quality of the achieved ceramic layer are presented in Figs. 2-4.

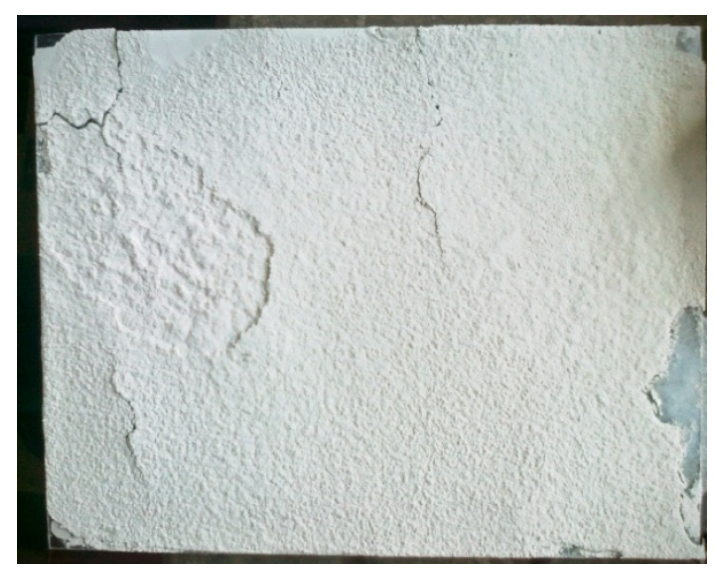

Fig. 2. Ceramic shell layer with pure Sizol030 binder

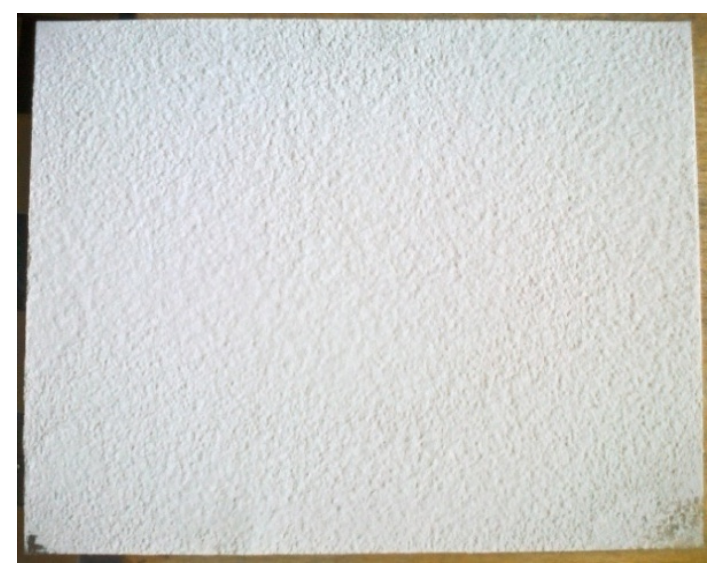

Fig. 3. Ceramic shell layer with Sizol030 binder modified with 0.5 mass $\%$ of $\mathrm{C}_{14} \mathrm{H}_{10} \mathrm{O}_{4}$

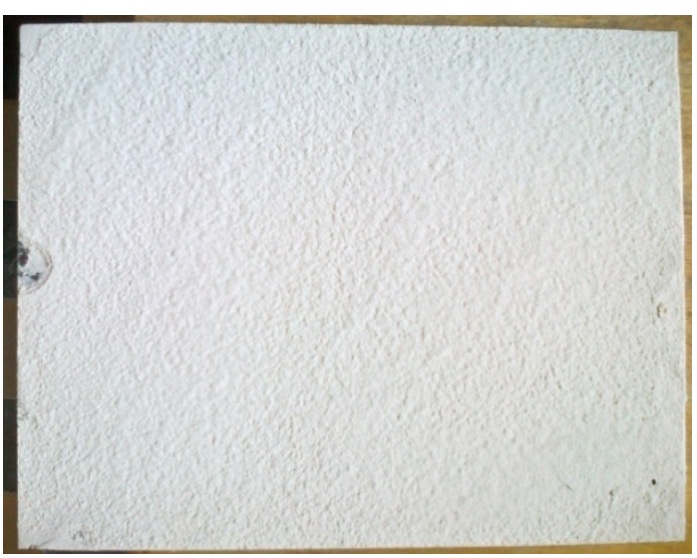

Fig. 4. Ceramic shell layer with Sizol030 binder modified with 1 mass $\%$ of $\mathrm{C}_{14} \mathrm{H}_{10} \mathrm{O}_{4}$

The above mentioned ceramic layers were obtained under the comparable conditions, at the identical air humidity, temperature, and at the same air motion rate over the specimens. The influence of benzoyl peroxide on the quality and thickness uniformity of the obtained ceramic layers was confirmed. The specimen layers obtained on the basis of pure colloidal silica are characterised by multiple cracks occurring during the dehydration process. The obtained surface is discontinuous and deformed. The specimens made of the material modified with benzoyl peroxide exhibit the uniform thickness of the applied layer and there is no visible defects in the form of cracks characteristic for the specimens obtained on the basis of the non-modified binder.

\section{Conclusion}

The performed examinations and the obtained results concerning the influence of benzoyl peroxide on the gelation rate of silica binder used in precision casting to prepare moulds for investment casting technology confirm the supposition that this addition can significantly reduce the preparation time of the thin-walled self-supporting shell mould based on Sizol 30 binder.

The examination allowed to draw the conclusions listed beneath.

1. Application of benzoyl peroxide in the composition of ceramic slurry in the quantity of 1 mass $\%$ of the pure binder, the latter being water solution of colloidal silica, increased effectively the rate of both gelation process proceeding and moulding material dehydration, so that the stability of specimen mass was reached for specimens no. 2 and 4 after about 90 and 50 minutes, respectively. The increase of benzoyl peroxide percentage in the slurry from 0.5 to 1 mass $\%$ shortens the dehydration time needed for achieving the mass stability of a sample.

2. There was observed an influence of benzoyl peroxide addition on the quality and thickness uniformity of the obtained ceramic layers. The layers made on the basis of pure colloidal silica develop multiple cracks during the dehydration process.

3. The use of benzoyl peroxide distinctly shortens the lifetime of moulding material, thus enforcing the technological change in the process of slurry application to the pattern sets from the 
dipping and stuccoing method to the spraying one, which would allow to apply the material more uniformly and would give the opportunity of better control with regard to the thickness of the obtained layer.

\section{References}

[1] European Investment Casters' Federation. (2004). Problems relating to waste, recycling and regulations. Foundry T. J. 178(3620), 405-407.

[2] Bozzo, A.T. (1989). Surfactants, Wetting and Foams, Remet Corp.

[3] Roberts, W. O., Griffin, E. R. (1988). USPat. 5118727.
[4] Guerra, M. (1994). Review of shell components, Atlanta: Investment Casting Institute.

[5] Piłkowski, Z. \& Nadolski, M. (2004). Some strength problems of shell molds for investment casting. Archiwum Odlewnictwa. 4(14), 413-419.

[6] Shaw, R. D., Duffey, D. J. (2004). USPat. 6769475.

[7] Duffey, D. J., Shaw, R. D. (2004). USPat. 6755237.

[8] Vandermeer, J. (1999). USPat. 6000457.

[9] Doles, R.S. (2003). USPat. 6540013.

[10] Karwiński, A., Adamczyk, Z., Stachańczyk, J. (2002). Patent PL 182949.

[11] Guerra, M. (1993). Remasol Adbond BV Binder - an Update. In 8th World Conference on Investment Casting London, June 199, London.

[12] Guerra, M. (1997). USPat. 5629369. 